\title{
ADSORÇÃO DE ALBUMINA DO SORO BOVINO (BSA) EM CARVÃO ATIVADO OBTIDO A PARTIR DO CAROÇO DO CAJÁ
}

\author{
T.P. OLIVEIRA ${ }^{1 *}$; J. F.BORGES ${ }^{2}$; K. A. MONTEIRO ${ }^{3}$; M. J. P. BRITO ${ }^{4}$; \\ C.M. VELOSO ${ }^{5}$; T.B.SILVA ${ }^{6}$.
}

${ }^{1,2,3}$ Universidade Estadual do Sudoeste da Bahia, Graduação em de Engenharia de Alimentos.

${ }^{4}$ Universidade Estadual do Sudoeste da Bahia, Programa de Pós-Graduação em Engenharia e Ciência de Alimentos

${ }^{5}$ Universidade Estadual do Sudoeste da Bahia, Departamento de Ciências Naturais

${ }^{6}$ Universidade Estadual do Sudoeste da Bahia, Graduação em Engenharia Ambiental *e-mail: thay.oliveira14@hotmail.com

\begin{abstract}
RESUMO
Este trabalho teve como objetivo avaliar a capacidade que o carvão ativado, obtido utilizando como precursor de carbono o caroço de cajá, tem em adsorver as moléculas da proteína do soro de leite: a Albumina do Soro Bovino (BSA). O carvão foi obtido por meio do processo de ativação química, utilizando hidróxido de potássio, como agente de ativação e foi caracterizado em relação ao seu teor de cinzas, umidade, rendimento do processo de síntese e determinou-se também o seu ponto de carga zero. Os testes adsortivos foram conduzidos para avaliar o efeito da variação do $\mathrm{pH}$ e da massa do adsorvente na eficiência do processo. O carvão ativado apresentou teores de cinza e umidade dentro dos padrões encontrados para carvões ativados obtidos a partir de resíduos agroindustriais e seu ponto de carga zero foi no valor de $\mathrm{pH}$ igual a 6,0. Nesse estudo notou-se que o pH 5,0 e a massa de 0,075g foram as condições mais adequadas para conduzir os testes de adsorção da proteína BSA.
\end{abstract}

\section{INTRODUÇÃO}

O soro do leite é um subproduto resultante da fabricação de queijos, por coagulação da caseína, obtido por adição de ácido ou de enzima (soro doce). Possui alto valor nutricional, conferido pela presença de proteínas com elevado teor de aminoácidos essenciais, destacando-se no conteúdo em sulfurados (WIT, 1998; NEVES, 2001). Devido à presença de biomoléculas de interesse comercial o soro do leite deixou de ser considerado como um resíduo, que sem uma destinação correta poderia conduzir a sérios problemas ambientais como a poluição das águas, geração de odor desagradável, bem como o comprometimento da estrutura físico- química do solo (COSTA et al, 2014), e passou a ser considerado como um coproduto da produção do queijo.

As proteínas presentes no soro do leite apresentam uma estrutura globular contendo algumas pontes de dissulfeto, que conferem certo grau de estabilidade estrutural. As frações, ou peptídeos do soro, são constituídas de: betalactoglobulina (BLG), alfalactoalbumina (ALA), albumina do soro bovino (BSA), imunoglobulinas (Ig's) e glicomacropeptídeos (GMP). Essas frações podem variar em tamanho, peso molecular e função, fornecendo às proteínas do soro características especiais. A BSA corresponde a cerca de $10 \%$ das proteínas do soro do leite. É um peptídeo de alto peso molecular $(66 \mathrm{kDa})$, 
rico em cistina (aproximadamente 6\%), e relevante precursor da síntese de glutationa. Possui afinidade por ácidos graxos livres e outros lipídeos, favorecendo seu transporte na corrente sanguínea (HARAGUCHI, ABREU \& PAULA, 2006).

O desenvolvimento de métodos capazes de fracionar, sem modificar as proteínas do soro pode contribuir para a recuperação desse valioso nutriente (CAPITANI et al., 2005). Dentre os métodos propostos para a separação e purificação das proteínas do soro, tem-se o método de adsorção.

O processo de adsorção é um método que pode ser definido como um fenômeno de transferência de massa do tipo sólido-fluido no qual substâncias existentes em fase fluida são transferidas para superfície de uma fase sólida, permitindo separá-las dos demais componentes dessas soluções. As substâncias que ligam a superfície são conhecidas como adsorbatos (soluto), enquanto a fase sólida que retém o adsorbato é conhecida como adsorvente (GOMIDE, 1987).

Os carvões ativados são uns dos adsorventes mais antigos usados na indústria. Eles são largamente usados nos tratamentos de água residencial e de efluentes industriais, além de servirem como catalisadores e suporte de catalisadores. Industrialmente, possuem um significante interesse e são aplicados em diversos casos, como no tratamento de poluentes atmosféricos e adsorção de compostos orgânicos. Além disso, podem ser utilizados na remoção de pesticidas e compostos orgânicos dissolvidos, e metais pesados (RODRIGUEZ-REINOSO, 1995).

O carvão ativado é um material poroso e de origem natural, importante devido às suas propriedades adsortivas. Sua característica física mais significativa é a elevada área superficial interna, desenvolvida durante o processo de síntese. A área é produzida por oxidação e o material carbonáceo desenvolve uma rede porosa que irá reter a substância a ser adsorvida (MUCCIACITO, 2006).

Para sua obtenção duas etapas básicas são necessárias: a carbonização pela pirólise do precursor e a ativação propriamente dita. De acordo com Fernandes (2005) a carbonização consiste no tratamento térmico (pirólise) do precursor. É uma etapa de preparação do material, onde se removem componentes voláteis e gases leves, produzindo uma massa de carbono fixo e uma estrutura porosa primária que favorece a ativação posterior. A ativação por sua vez corresponde ao processo subsequente a pirólise e consiste em submeter o material carbonizado a reações secundárias, visando o aumento da área superficial. Assim, é nesta etapa que o aumento da porosidade acontece (FERNANDES, 2005).

De uma maneira geral, quase todos os compostos com alto teor de carbono podem ser transformados em carvão ativados. São exemplos: ossos de animais, serragem, algas, turfa, casca de coco, casca de babaçu, diversas madeiras, caroço de frutas, carvões minerais, resíduos de petróleo, dentre outros materiais carbonáceos. A escolha do material a ser ativado depende da sua pureza, preço, e potencial de ativação (SRINIVASAKANNAN e ABU BAKAR, 2004; KHEZAMI et al., 2005; GURSES et al., 2005).

Diante do exposto, este trabalho teve como objetivo sintetizar carvão ativado utilizando como precursor o caroço do cajá e determinar a influência da variação do $\mathrm{pH}$ e da massa no processo de adsorção da Albumina do Soro Bovino.

\section{MATERIAIS E MÉTODOS}

$\mathrm{Na}$ síntese do carvão ativado foi utilizado o caroço do cajá como precursor de carbono. O mesmo foi seco naturalmente, triturado em moinho e em seguida peneirado em uma peneira de 40 mesh. O resíduo foi 
impregnado com hidróxido de potássio $(0,5 \mathrm{~g}$ de agente: $1 \mathrm{~g}$ de precursor) permanecendo na estufa $48 \mathrm{~h}$ a $110{ }^{\circ} \mathrm{C}$. A carbonização do material foi realizada em forno mufla com taxa de aquecimento de $5^{\circ} \mathrm{C} \cdot \mathrm{min}^{-1}$ até $500{ }^{\circ} \mathrm{C}$, permanecendo nesta temperatura por $60 \mathrm{~min}$ sob fluxo de nitrogênio $\left(50 \mathrm{ml} \cdot \mathrm{min}^{-1}\right)$. Após a carbonização o material obtido foi lavado com uma solução de ácido clorídrico $0,1 \mathrm{~mol} . \mathrm{L}^{-1} \mathrm{e}$ levado à ebulição por um período de $60 \mathrm{~min}$ sobre refluxo. Por fim, o carvão ativado obtido foi lavado com água quente até atingir o $\mathrm{pH}$ 7,0 e seco a $105^{\circ} \mathrm{C}$ durante $24 \mathrm{~h}$.

Os teores de umidade e cinzas do carvão obtido foram determinados de acordo com as normas do Instituto Adolfo Lutz (2004). O rendimento do processo de síntese do carvão ativado a partir do caroço do cajá, foi calculado através da Equação 1:

$$
R_{c}(\%)=\left(\frac{m_{c}}{m_{p}}\right) \times 100
$$

Em que: Rc é o rendimento de carvão $(\%), \mathrm{m}_{\mathrm{c}}$ é a massa do carvão obtido ( $\mathrm{g}$ ) e $\mathrm{m}_{\mathrm{p}}$ é a massa do material precursor $(\mathrm{g})$.

No estudo do ponto de carga zero foi realizado o "experimento dos 11 pontos". Prepararam-se soluções de $\mathrm{NaCl} 0,10$ mol. $\mathrm{L}^{-1}$ com diferentes valores de $\mathrm{pH}(1,2,3,4,5,6$, $8,9,10,11$ e 11) usando água deionizada. $\mathrm{O}$ pH de cada solução foi ajustado no valor requerido. Aproximadamente $50 \mathrm{mg}$ da amostra de carvão ativado foi misturada com $50 \mathrm{~mL}$ de soluções de $\mathrm{NaCl}$ 0,10 mol.L $\mathrm{L}^{-1} \mathrm{em}$ diferentes valores de $\mathrm{pH}$ inicial. Os tubos de ensaio foram agitados por $24 \mathrm{~h}$ em um agitador orbital. $\mathrm{O} \mathrm{pH}$ final foi medido e construído o gráfico, colocando-se o $\mathrm{pH}$ final versus o $\mathrm{pH}$ inicial.

Para realizar o estudo do efeito do $\mathrm{pH}$ no processo adsortivo foram adicionados $0,025 \mathrm{~g}$ de carvão em tubos de ensaio contendo $5 \mathrm{~mL}$ da solução de proteína BSA, na concentração de $500 \mathrm{mg} . \mathrm{L}^{-1}$. Os tubos foram mantidos sob agitação constante $(20 \mathrm{rpm})$ à $25^{\circ} \mathrm{C}$ por $24 \mathrm{~h}$ em agitador orbital, em seguida foram centrifugados sendo o sobrenadante filtrado. A quantificação das proteínas foi realizada por leitura direta em espectrofotômetro no comprimento de onda de $280 \mathrm{~nm}$. Para avaliar o efeito da massa na adsorção da proteína, diferentes massas de carvão $(0,025 \mathrm{~g} ; 0,050 \mathrm{~g}$ e $0,075 \mathrm{~g}$ ) foram adicionadas em tubos contendo $5 \mathrm{~mL}$ da solução de proteína (BSA) com concentração inicial de $500 \mathrm{mg} . \mathrm{L}^{-1}$ no $\mathrm{pH}$ escolhido no teste anterior, seguindo a mesma metodologia descrita no estudo do $\mathrm{pH}$.

\section{RESULTADOS E DISCUSSÃO}

Na Tabela 1 são apresentados os resultados para caracterização e rendimento do carvão obtido

Tabela 1. Teores de umidade, cinzas e rendimento do carvão ativado.

\begin{tabular}{cccc}
\hline Amostra & $\begin{array}{c}\text { Umidade } \\
(\%)\end{array}$ & $\begin{array}{c}\text { Cinzas } \\
(\%)\end{array}$ & $\begin{array}{c}\text { Rendimento } \\
(\%)\end{array}$ \\
\hline Cajá & 2,60 & 2,05 & 15,05
\end{tabular}

Fonte: Autor (2015)

O teor de umidade do carvão ativado é frequentemente requerido para definir e expressar suas propriedades com relação ao peso líquido do carbono. Tendo em vista que o total de água presente em amostras de carvão ativado é resultante da combinação entre umidade superficial e a inerente ao produto. A incorporação de água ocorre durante as etapas de fabricação, transporte e armazenamento. Já o excedente de água, é resultado das propriedades naturais do produto (PIZA, 2008). Cabe salientar que carvões ativados comerciais apresentam na sua especificação técnica a indicação de um teor de umidade máximo de $10 \%$ (SILVA, 2009). No resultado do experimento, o teor de umidade foi satisfatório.

Segundo Jaguaribe et al. (2005), o teor de cinzas é um indicador da qualidade do carvão ativado e, em geral, a porcentagem do 
carvão ativado comercial é de até $15 \%$. Ao observar o resultado encontrado no carvão produzido, verifica-se que o resultado foi satisfatório, visto que segundo Santos et al. (2013) quanto mais baixo o teor de cinzas, maior sua eficiente na adsorção.

$\mathrm{O}$ rendimento do processo de síntese foi de 15,05 \%. Segundo Claudino (2003) os parâmetros importantes que irão determinar esse fator do produto carbonizado são a taxa de aquecimento, a temperatura final, o fluxo de gás de arraste e a natureza da matéria prima.

O ponto de carga zero pode ser definido como a atividade dos íons determinadores de potencial (que são os íons que constituem a carga superficial), em solução, quando essa carga superficial é zero (FUERSTENAU, ROSENBAUM \& YOU, 1988). Sendo assim, analisa-se no gráfico (Figura 1) que o ponto de carga zero para o carvão ativado obtido a partir do caroço de cajá está na região de pH 6,0.

Figura 1 Ponto de carga zero do carvão.

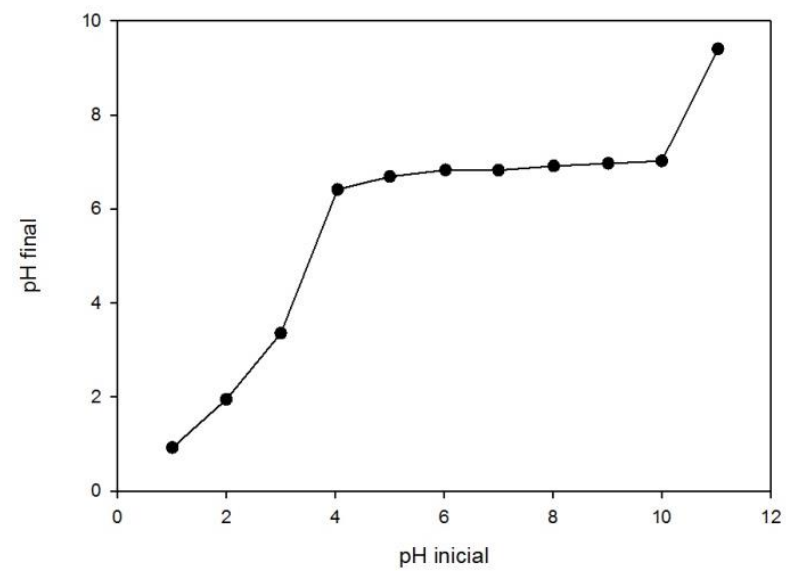

Fonte: Autor (2015)

Os resultados do estudo do efeito do $\mathrm{pH}$ no processo de adsorção da BSA estão apresentados na Tabela 2.

Observa-se que no $\mathrm{pH} \mathrm{5,0} \mathrm{obteve} \mathrm{maior}$ capacidade e eficiência adsortiva. Esse valor de $\mathrm{pH}$ é aproximadamente igual ao ponto isolelétrico da BSA $(5,13)$ e é inferior o ponto de carga zero do carvão $(6,0)$, demonstrando que as características superficiais do carvão (tamanho de poros e área superficial) é que deve governar o processo adsortivo. Os baixos valores de eficiência podem ser justificados, pois a molécula de BSA apresenta uma massa molar de $64 \mathrm{kDa}$, dificultando seu acesso aos poros do carvão (geralmente microporoso).

Tabela 2. Concentração na solução (C), capacidade adsortiva (q) e eficiência de adsorção (efic) da proteína BSA.

\begin{tabular}{ccccc}
\hline Amostra & $\mathrm{pH}$ & $\begin{array}{l}\mathrm{C}\left(\mathrm{mg} \cdot \mathrm{L}^{-}\right. \\
\left.{ }^{1}\right)\end{array}$ & $\begin{array}{l}\mathrm{q} \\
\left(\mathrm{mg} . \mathrm{g}^{1}\right)\end{array}$ & $\begin{array}{l}\text { Efic } \\
(\%)\end{array}$ \\
\hline $\mathrm{CA}$ & 3 & 459,3 & 8,1 & 8,1 \\
$\mathrm{CA}$ & 5 & 369,1 & 26,2 & 26,1 \\
$\mathrm{CA}$ & 7 & 372,0 & 25,4 & 25,5 \\
\hline
\end{tabular}

Fonte: Autor (2015)

Como em $\mathrm{pH}=5,0$ foram obtidos os maiores valores de capacidade adsortiva e eficiência, o mesmo foi escolhido para a realização do estudo de massa.

Na Tabela 3 são apresentados os resultados obtidos por meio do estudo de massa sobre a adsorção da BSA. Pode se observar através dos resultados que ao se aumentar a massa do adsorvente, aumenta-se a eficiência do processo de adsorção, obtendo-se uma eficiência máxima de $57,4 \%$ com uma massa de $0,075 \mathrm{~g}$. Este comportamento se deve ao aumento nos sítios adsortivos proporcionado pelas massas maiores do adsorvente.

Tabela 3. Concentração na solução (C), capacidade adsortiva (q) e eficiência de adsorção (efic) da proteína BSA em amostra do carvão obtido do cajá.

\begin{tabular}{ccrrr}
\hline Amostra & $\begin{array}{c}\text { Massa } \\
(\mathrm{g})\end{array}$ & $\begin{array}{c}\mathrm{C} \\
\left(\mathrm{mg} . \mathrm{L}^{-1}\right)\end{array}$ & $\begin{array}{c}\mathrm{q} \\
\left(\mathrm{mg} \cdot \mathrm{g}^{1}\right)\end{array}$ & $\begin{array}{c}\text { Efic } \\
(\%)\end{array}$ \\
\hline $\mathrm{CA}$ & 0,025 & 369,1 & 26,2 & 26,1 \\
$\mathrm{CA}$ & 0,050 & 337,1 & 16,2 & 32,5
\end{tabular}




\begin{tabular}{lllll} 
CA $\quad 0,075$ & 212,5 & 19,1 & 57,4 \\
\hline
\end{tabular}

Fonte: Autor (2015)

\section{CONCLUSÃO}

Diante do estudo é possível concluir que a capacidade adsortiva do carvão ativado obtido a partir do caroço de cajá no processo de adsorção da BSA foi considerada reduzida, pois o tamanho da molécula da proteína dificulta o seu aceso aos poros do carvão. Desta forma esse carvão poderia ser empregados em processos em que se deseja separar proteínas presentes no soro do leite e que tenham tamanhos menores que a BSA.

\section{REFERÊNCIAS}

ANDRADE, S.N.; VELOSO, C.M.; BONOMO, R.C.F. Síntese de carvão ativado a partir do endocarpo de coco Lixiviado com NaOH. Resumo expandido para $54^{\mathrm{a}} \mathrm{CBQ}$ (2014).

CAPITANI, C. D., PACHECO, M. T. B., GUMERATO, H. F., VITALI, A., SCHMIDT, F. L. Recuperação de proteínas do soro de leite por meio de coacervarão com polissacarídeo. Pesquisa agropecuária brasileira, v.40, n.11, p.1123-1128, 2005.

CLAUDINO, A. Preparação de carvão ativado a partir de turfa e sua utilização na remoção de poluentes. Dissertação (Mestrado) - Programa de Pós-graduação em Engenharia Química da Universidade Federal de Santa Catarina, Florianópolis - SC, pp.100, 2003.

COSTA, C. M.; AZEVEDO, C. A.; AZEVEDO, L. A.; LINS, M. F.; VEIGA, R. L.; LIMA, S. F.. Soro do leite e os danos causados ao meio ambiente. (2014) Disponível em: <http://www2.unifesp.br/home_diadema/eba2
014/br/resumos/R0038-1.PDF>. Acesso em: 15 jun. 2015.

DE LAMOTTE, F. Single step pirification of a series of wheat recombinant pro expanded bed absorption chromatography. Journal of Chromatography B-Analytical Technologies in the Biomedical and Life Sciences. V. 808, p 29-33, 2005.

FERNANDES, R. Adsorventes alternativos para remoção de fenol em solução aquosa. Programa de Pós-Graduação Engenharia química, UFSC, Florianópolis-SC, 2005. Dissertação de mestrado.

FUERSTENAU, D.W.; ROSENBAUM, J.M.; YOU, Y.S. Electrokinetic Behavior of Coal. Energy\&Fuels, v.2, p. 241-245, 1988.

GOMIDE, R. Operações unitárias: operações de transferência de massa. $1^{\mathrm{a}}$ ed. São Paulo: Dag Gráfica e Editora ltda., 1988 v. 4, p. $311-315$.

GURSES, A.; DOCGAR, C.; KARACA, S.; AÇIKYILDIZ, M.; BAYRAK, R. Production of granular activated carbon from waste Rosa canina sp. seeds and its adsorption characteristics for dye. Journal of Hazardous Materials B131 p.254-259, Novembro 2005.

HARAGUCHI, F. K.; ABREU, W. C.; PAULA, H. Whey protein: composition, nutritional properties, appications in sports and benefits for human health. Rev. Nutr. vol.19 no.4 Campinas Jul/Agos. 2006.

JAGUARIBE， E. F.; MEDEIROS， L.L.; BARRETO, M.C.S.; ARAUJO, L.P. The performance of activated carbons from sugarcane bagasse, babassu, and coconut shells in removing residual chlorine. Brazilian Journal of Chemical Engineering. v. 22, n. 1, Sao Paulo, 2005. 
JUNIOR, O. F. C. Produção de carvão ativado a partir de produtos residuais de espécies nativas da região amazônica. Programa de Pós-Graduação em Engenharia Mecânica e de Materiais da Universidade Tecnológica Federal do Paraná, Curitiba, pp. 48, 2010.

KHEZAMI, L.; CHETOUANI, A.; TAOUK, B.; CAPART, R. Production and characterisation of activated carbon from wood components in powder: Cellulose, lignin, xylan. Powder Technology v.157 p. 48 - 56, Junho 2005.

LEGROURI, K.; KHOUYA, E.; EZZINE M.; HANNACHE, H.; DENOYEL, R.; PALLIER, R.; NASLAIN R. Production of activated carbon from a new precursor molasses by activation with sulphuric acid. Journal of Hazardous Materials, v.118 p.259 - 263, 2005.

MUCCIACITO, J. C. Conceitos e aplicações do carvão ativado. Rev. Meio Filtrante, ano V, Ed nº 22, Setembro/Outubro. 2006.

NEVES, B.S. Aproveitamento de subprodutos da indústria de laticínios. In: EMBRAPA GADO DE LEITE. Sustentabilidade da pecuária de leite no Brasil: qualidade e segurança alimentar. Juiz de Fora, MG, 2001. p.97-108.

PIZA, A. V. T. Avaliação da capacidade adsortiva de carvões ativados para a remoção de Diuron e Hexazinona. Dissertação (Mestrado) - Centro de Ciências Exatas Naturais e Tecnológicas da Universidade de Ribeirão Preto, Ribeirão Preto, 2008.

RODRIGUEZ-REINOSO, F.; IN: W. PATRICK JR. (Ed.), Porosity in Carbons:
Characterization and Applications, Londres: Edward Arnold 1995, Cap: 10.

SANTOS, M. P. F.; SILVA, N. M.; LIMA, E. R. N.; VELOSO, C. M. Obtenção de carvão ativado a partir da semente de seriguela (spondias purpurea l.) e seu emprego no processo adsortivo do corante vermelho Dianix CC. Anais da $65^{\mathrm{a}}$ Reunião Anual da SBPC, 2013.

SILVA, J. Estudo da eficiência e aplicabilidade de carvão ativado de pirólise de casca de arroz em barreiras reativas na remoção de contaminantes em solos. Tese (Doutorado). Universidade federal do Rio Grande do Sul. Porto Alegre - RS, 2009.

SRINIVASAKANNAN, C.; ABU BAKAR, M.Z. Production of activated carbon from rubber wood sawdust. Biomass and Bioenergy, v.27 p.89 - 96, Janeiro 2004.

WIT, J.N. de. Nutritional and functional characteristics of whey proteins in food products. Journal of Dairy Science, v.81, p.597-608, 1998. 